\title{
Prenatal diagnosis of diastrophic dysplasia with polymorphic DNA markers
}

\author{
Johanna Hästbacka, Riitta Salonen, Pekka Laurila, Albert de la Chapelle, Ilkka Kaitila
}

\begin{abstract}
Ultrasonography is a non-invasive method for prenatal detection of diastrophic dysplasia (DTD) in the second trimester of pregnancy. As there is a need for genetic counselling as early as possible we wished to develop a method based on molecular analysis. Five fetuses in families with a previous history of DTD were studied by typing them and their relevant family members for DNA markers closely linked to the DTD gene. The DNA analyses predicted that three of the fetuses were unaffected and two affected. These results were concordant with those obtained by ultrasonography, and the phenotype of the fetus was correctly predicted in all cases. DNA analysis provides a reliable means of prenatal diagnosis in the first trimester of pregnancy.
\end{abstract}

(f Med Genet 1993;30:265-8)

Diastrophic dysplasia (DTD) is a severe autosomal recessive chondrodysplasia characterised by disproportionate short stature, generalised joint dysplasia, and deformities of the spine and extremities. ${ }^{1}$ Tracheomalacia and kyphosis of the cervical spine cause a significant risk of fatal respiratory and neurological complications. Most patients undergo repeated orthopaedic surgery during childhood, often with unsatisfactory results. ${ }^{2}$ The diagnosis is based on clinical and radiographic findings which can be readily distinguished from those of other chondrodysplasias. DTD occurs at low prevalence in most populations, but is exceptionally common among Finns with a carrier frequency of about 1 in 70 . The biochemical defect and pathogenesis of DTD are unknown.

Owing to the severe physical handicap caused by DTD most families with an affected child request prenatal diagnosis in subsequent pregnancies. This can be provided by ultrasonography which, however, is feasible only after the first trimester. ${ }^{3-6}$ Thus, the diagnosis can only be attained relatively late extending the period of anxiety of the families, and delaying the eventual abortion to midpregnancy. The delay is critical regarding the method by which the termination of pregnancy is performed.

The DTD gene has been localised to distal $5 q$ by linkage analysis. ${ }^{78}$ The immediate region surrounding DTD is well covered with poly- morphic DNA markers several of which do not recombine with the disease gene. Recently strong linkage disequilibrium was detected between the colony stimulating factor 1 receptor locus $(C S F 1 R$ ) and DTD (table 1) indicating that $C S F 1 R$ is the closest known locus to DTD. ${ }^{9}$ The aim of this study was to establish prenatal diagnosis that would allow genetic counselling during the first trimester.

\section{Materials and methods}

\section{FAMILIES}

Pedigrees of the five families studied are shown in fig 1 . In families 1 to 3 prenatal diagnosis by DNA analysis was done in parallel with ultrasonography. In families 4 and 5 the actual diagnosis was made by ultrasonography and the fetuses were found to be affected. DNA analysis was performed retrospectively in these two families.

\section{DNA SAMPLES}

The source of DNA was blood leucocytes for parents and sibs, cultured amniotic cells from the fetus of family 1 , chorion villus samples from the fetuses in families 2 and 3, and skin samples obtained at necropsy from the fetuses in families 4 and 5. Amniocentesis was performed in the 17th gestational week and the placental biopsies in the 12th and 16th gestational weeks. DNA was extracted by standard methods.

DNA MARKERS

The polymorphisms used in this study ${ }^{9-14}$ are described in table $2 \mathrm{~A}$ and the two point linkage data in table $2 \mathrm{~B}$. The most likely order of marker loci and their location in relation to the DTD gene on the sex averaged map as derived from linkage analysis is $G R L-8 \cdot 2 \mathrm{cM}-D T D$ $0.7 \mathrm{cM}-C S F 1 R-4.4 \mathrm{cM}-S P A R C$ (unpublished results).

Table 1 Frequencies of the four StyI-EcoRI haplotypes at CSF1R determined in 152 Finnish DTD chromosomes and 123 control chromosomes.

\begin{tabular}{lcc}
\hline Haplotype & $\begin{array}{c}\text { DTD } \\
\text { chromosomes (\%) }\end{array}$ & $\begin{array}{c}\text { Normal } \\
\text { chromosomes (\%) }\end{array}$ \\
\hline $\mathrm{A}=1-1$ & 95 & 3 \\
$\mathrm{~B}=1-2$ & 1 & 23 \\
$\mathrm{C}=2-1$ & 0 & 6 \\
$\mathrm{D}=2-2$ & 5 & 68 \\
\hline
\end{tabular}

Correspondence to Dr Hästbacka.

Received 8 October 1992 Accepted 28 October 1992 


\section{SPARC/MspI SPARC/TaqI CSF1R/NCOI CSF1R/ECORI CSF1R/TAGA CSF1R/Styl CSF1R/CCTT CSF1R/CA GRL/Bcll}

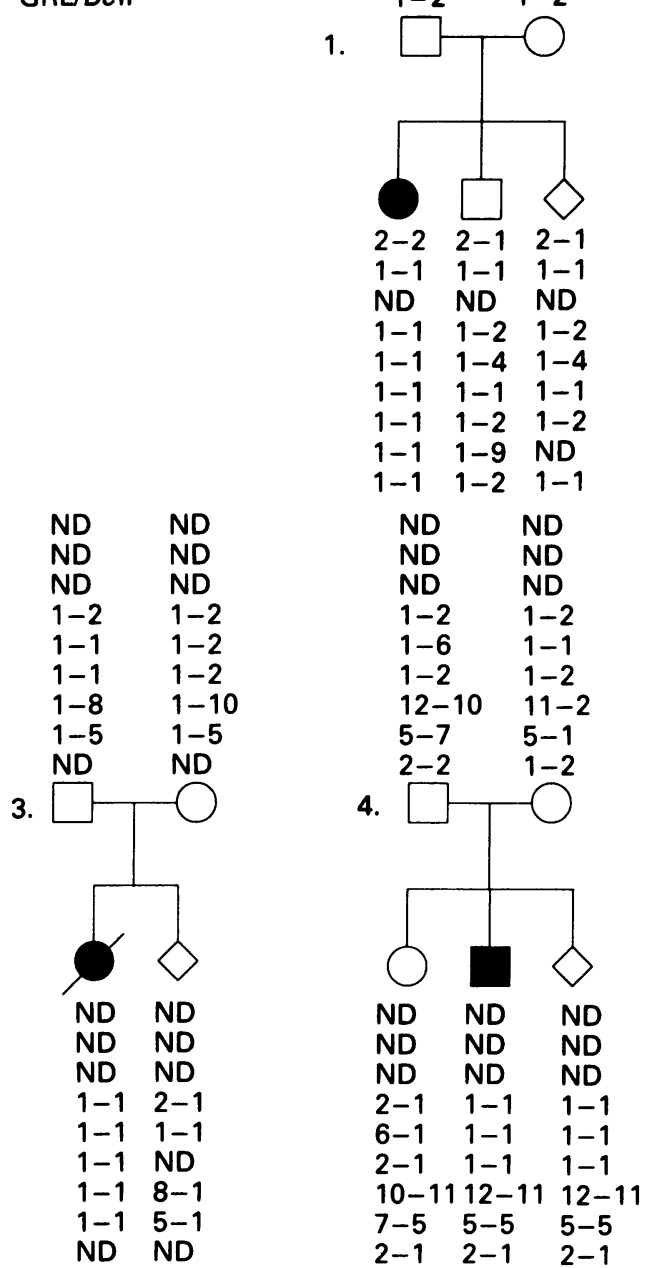

$\begin{array}{ll}\text { ND } & \text { ND } \\ \text { ND } & \text { ND } \\ 2-2 & 1-2 \\ 1-2 & 2-2 \\ 1-5 & 5-5 \\ 1-1 & 2-2 \\ 1-2 & 1-12 \\ 1-9 & 7-4 \\ \text { ND } & \text { ND }\end{array}$

2.

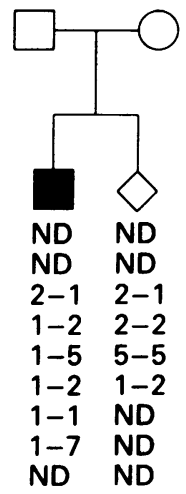

ND ND

$\begin{array}{ll}\text { ND } & \text { ND } \\ \text { ND } & \text { ND } \\ \text { ND } & \text { ND } \\ 1-2 & 1-2 \\ 1-1 & 1-4 \\ 1-2 & 1-2 \\ 10-1 & 10-9 \\ 1-5 & 1-7 \\ \text { ND } & \text { ND }\end{array}$

5.

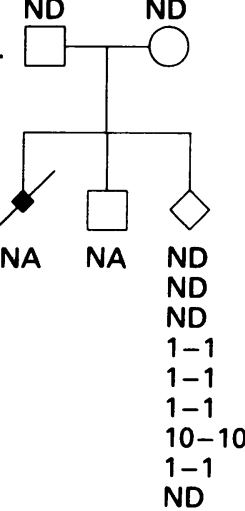

DNA METHODS

Southern analyses were performed using standard protocols. ${ }^{15}$ Polymerase chain reaction (PCR) amplifications were done in a total volume of $10 \mu \mathrm{l}$ with $20 \mathrm{ng}$ of genomic DNA, $1 \mathrm{pmol}$ of each primer one of which was kinase labelled with $\gamma-{ }^{32} \mathrm{P}-\mathrm{ATP}$, in $100 \mu \mathrm{mol} / \mathrm{l}$ dNTPs, $\quad 50 \mathrm{mmol} / 1 \mathrm{KCl}, \quad 10 \mathrm{mmol} / 1$ Tris$\mathrm{HCl}, \mathrm{pH} 8.3,1.5 \mathrm{mmol} / 1 \mathrm{MgCl}_{2}, 0.001 \%$ gelatin, with $0.25 \mathrm{U} \mathrm{Taq}$ polymerase. The PCR products were fractionated on $6 \%$ polyacrylamide gels containing $7 \mathrm{~mol} / 1$ urea followed by autoradiography for two to 12 hours.

\section{RISK CALCULATIONS}

The probability of the fetus being affected, an unaffected carrier, or non-carrier was calculated using the risk calculation option of the program MLINK of the LINKAGE package.$^{16}$ In family 1 the calculation was originally based on data of the flanking marker loci $G R L$ and $S P A R C$. At that time the close linkage between $D T D$ and $C S F 1 R$ had not yet been detected, which also caused the distances between DTD and the flanking markers used in the calculations to be slightly different from the ones on the current map. In the remaining four cases calculations were based solely on data on CSF1R polymorphisms. For family 5 linkage disequilibrium data were used for estimating the phase of $C S F 1 R$ polymorphisms and $D T D$. Up to six polymorphisms at $C S F 1 R$ were tested, haplotyped, and considered a single locus. The fetus of family 1 was also tested retrospectively for $C S F 1 R$ polymorphisms and a new risk calculation performed.

\section{Results}

The structure of four of the five families allowed direct risk calculations based on linkage analysis. At a probability level of more than $95 \%$ three fetuses were predicted to be unaffected carriers while one was predicted to be affected (table 3 ). The results of DNA analysis were concordant with those of ultrasonography, and with the phenotypes of the babies delivered and the aborted fetus examined at necropsy.

The structure of family 5 did not allow standard risk calculations (fig 1). There was no DNA available from the first affected fetus (diagnosed at necropsy after termination of pregnancy based on ultrasonographic findings) nor from the healthy brother, but only from the parents and the fetus under study. This rendered the family formally uninformative for linkage analysis. In this case, however, the strength of the linkage disequilibrium observed in the Finnish population ${ }^{9}$ (table 1) could be exploited to establish the phase of $D T D$ and the polymorphisms at $C S F 1 R$, which in turn allowed calculation of the risk by linkage analysis. The probability $(P)$ of one parent carrying $D T D$ on a chromosome with haplotype $\mathrm{A}$ (table 1 ) is:

$\frac{P\left(A_{D T D} D_{\text {norm }}\right)}{P\left(A_{D T D} D_{\text {norm }}\right)+P\left(B_{D T D} C_{\text {norm }}\right)+P\left(C_{D T D} B_{\text {norm }}\right)+P\left(D_{D T D} A_{\text {norm }}\right)}$

* Up to six polymorphisms at the CSFIR locus were haplotyped for linkage calculations. One crossove within $C S F I R$ was observed causing part of $C S F 1 R$ to recombine with $D T D .{ }^{9}$ In the linkage calculation this was treated as a regular recombination between the two loci.

$\dagger$ Haplotypes constructed from two polymorphisms at the locus were used in linkage calculations.

$\overline{P\left(A_{D T D} D_{\text {norm }}\right)+P\left(B_{D T D} C_{n o r m}\right)+P\left(C_{D T D} B_{\text {norm }}\right)+P\left(D_{D T D} A_{\text {norm }}\right)}$ 
Table 3 The risks of fetuses being affected, unaffected carriers, or non-carriers based on results from polymorphisms at CSFIR. The figures in parentheses for family 1 are the results of the initial risk calculation based on markers GRL and SPARC flanking DTD.

\begin{tabular}{lccccc}
\hline & Family 1 & Family 2 & Family 3 & Family 4 & Family 5 \\
\hline Affected & $1.3 \%(19 \cdot 3 \%)$ & $1.7 \%$ & $1.7 \%$ & $97.3 \%$ & $97.6 \%$ \\
Unaffected carrier & $97.3 \%(79.7 \%)$ & $96.5 \%$ & $96.5 \%$ & $2.7 \%$ & $2.4 \%$ \\
Non-carrier & $1.3 \%(1 \%)$ & $1.7 \%$ & $1.7 \%$ & $0 \%$ & $0 \%$ \\
\hline
\end{tabular}

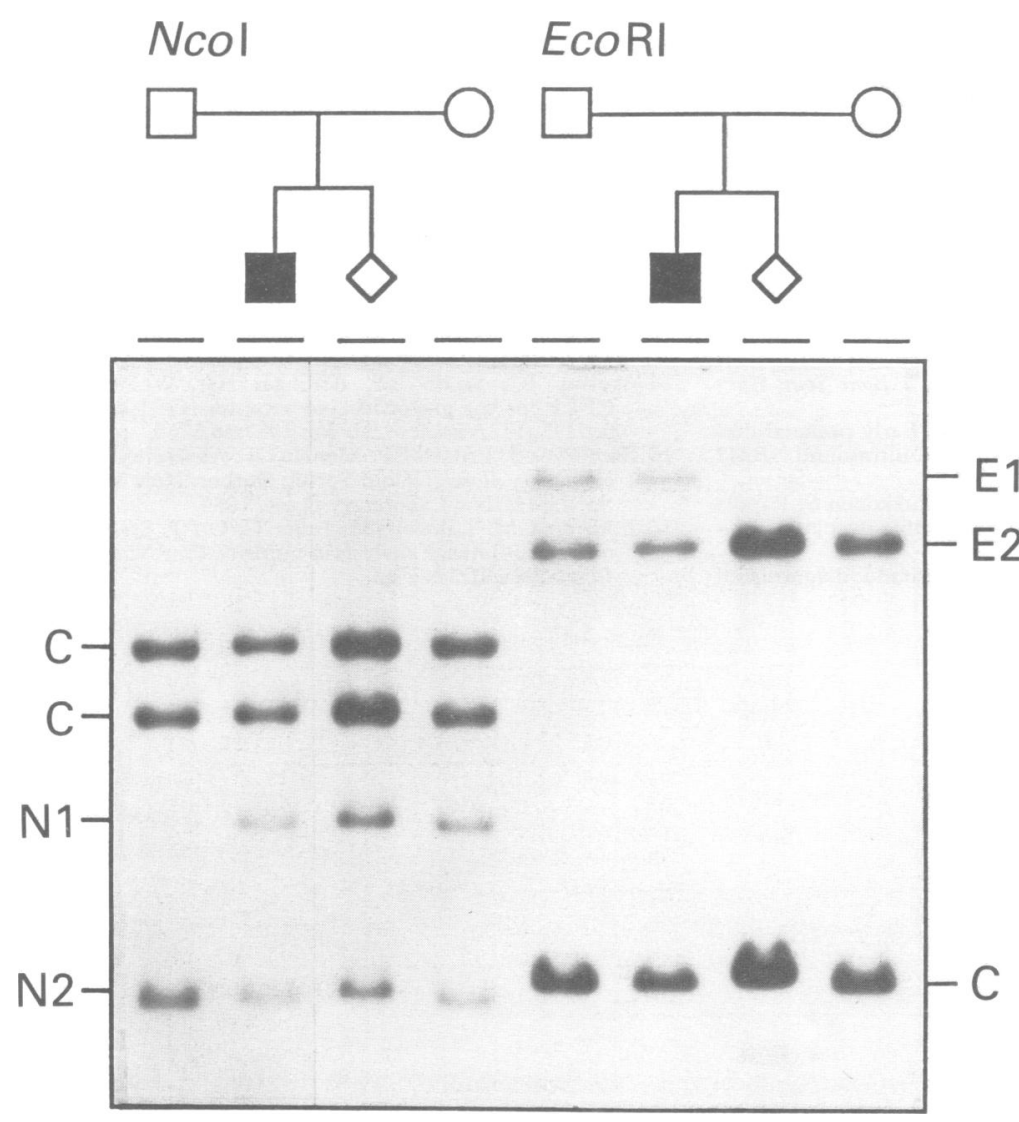

Figure 2 A Southern blot analysis from family 2. Restriction enzyme digestions were done with enzymes NcoI and EcoRI, electrophoresed, blotted, and hybridised with the $C D N A$ clone pcfms-104 from CSFIR. The polymorphic fragments shomn by NcoI digestion are N1 $(4 \cdot 1 \mathrm{~kb})$ and N2 (2.9 kb) and the ones shomn by EcoRI digestion E1 (29kb) and E2 (16 kb). C stands for constant bands. The fetus inherited the same allele from the mother as the affected brother, but a different allele from the father and therefore was predicted to be an unaffected DTD carrier.
Thirteen fetuses were unaffected. A major handicap of the method is that the time of diagnosis occurs so late that a possible termination can only be done in the second trimester of pregnancy. This study was undertaken to determine if earlier, DNA based diagnosis for DTD might be feasible.

Five pregnancies at risk for DTD were studied by typing the families for DNA polymorphisms closely linked to $D T D$. With the exception of the initial diagnosis in family 1 , the DNA diagnoses were based on the information derived from several polymorphisms at a single locus, CSF1R. This method was chosen because, despite one recombination having been observed between $C S F 1 R$ and $D T D$, or strictly between $D T D$ and part of $C S F 1 R,{ }^{9}$ both the linkage disequilibrium and genetic mapping data strongly indicate that $C S F 1 R$ is the closest available marker to $D T D$. It contains at least six polymorphisms: three two allele RFLPs and three highly polymorphic simple sequence length polymorphisms (SSLPs). In the course of our studies on Finnish DTD families, we have typed 123 DTD parents and not found a single person who is not informative for at least one of these polymorphisms. ${ }^{9}$ The SSLPs are typed by PCR which allows results to be rapidly obtained from minimal amounts of DNA. The limited availability of DNA from fetuses is a common problem in diagnosis based on Southern blot hybridisation; therefore the existence of useful PCRable markers is an advantage. However, an issue regarding the choice of method might be raised in that some SSLPs have high mutation rates ${ }^{9}$ which might conceivably lead to diagnostic errors. Ideally both types of polymorphism should be used, subject to sample availability. Further experience with SSLPs will eventually determine the empirical risk of problems arising from these circumstances.

The risk calculations correctly predicted the phenotype of the fetus in all families. The strong linkage disequilibrium between $C S F 1 R$ and $D T D$ allowed phase estimation and risk calculation in a family with a history of DTD but no sample available from the first affected fetus. However, even in Finland linkage disequilibrium cannot be exploited in population screening. Despite the strength of this linkage disequilibrium four out of five Finnish chromosomes 5 carrying the high risk haplotype ' $A$ ' are non-DTD chromosomes.

Based on this study we consider the prenatal diagnosis of DTD based on the polymorphisms at CSF1R to be reliable enough in the Finnish population to be used as an alternative to ultrasonography in families with an affected child. The diagnosis can be established at least a month earlier than by ultrasonography if chorion villus sampling is performed at 10 weeks' gestation. With the PCR based polymorphisms results can be obtained in a few days. Earlier diagnosis reduces the psychological burden of the families caused by the period of waiting. The time that can be saved by using DNA analysis is critical regarding the 
method of termination of the pregnancy if indicated and chosen.

We thank Drs Aki Mustonen, Maila Penttinen, and Pertti Aula for samples, Ms Elvi Karila for assistance in the laboratory, Drs G Long and $S$ Naylor for the probe pHVON-92, and Dr R M Evans for the probe phGr1.2. The probe pcfms-104 was purchased from the American Type Culture Collection. This study was financially supported by grants from the Sigrid Juselius Foundation, the Finska Läkaresällskapet, the Finnish Medical Foundation, the Alfred Kordelin Foundation and the Oskar Öflund Foundation.

1 Walker BA, Scott CI, Hall JG, Murdoch JL, McKusick VA. Diastrophic dwarfism. Medicine (Baltimore) 1972 51:41-59.

2 Ryöppy S, Merikanto J, Marttinen E, Kaitila I. Foot deformities in diastrophic dysplasia. $\mathcal{f}$ Bone foint Surg (Br) 1992;74:441-4.

3 O'Brien GD, Rodeck C, Queenan JT. Early prenatal diagnosis of diastrophic dwarfism by ultrasound. $B M$ 1980;280:1300

4 Kaitila I, Ämmälä P, Karjalainen O, Liukkonen S, Rapola J. Early prenatal detection of diastrophic dysplasia. Prenat Diagn 1983;3:237-44.

5 Gollop TR, Eigier A. Prenatal ultrasound diagnosis of diastrophic dysplasia at 16 weeks. Am $\mathcal{F}$ Med Genet 1987; 27:321-4

6 Gembruch U, Niesen M, Kehrberg H, Hansmann M Diastrophic dysplasia: a specific prenatal diagnosis by ultrasound. Prenat Diagn 1988;8:539-45.

7 Hästbacka J, Kaitila I, Sistonen P, de la Chapelle A Diastrophic dysplasia gene maps to the distal long arm of chromosome 5. Proc Natl Acad Sci USA 1990;87:8056-9.

8 Hästbacka J Sistonen P, Kaitila I Weiffenbach B, KK KK, de la Chapelle A. A linkage map spanning the locus f3. diastrophic dysplasia (DTD). Genomics 1991;11:968-

Hästbacka J, de la Chapelle A, Kaitila I, Sistonen P, Weaver A, Lander E. Linkage disequilibrium mapping in isolated founder populations: diastrophic dysplasia in Finland. Nature Genet 1992;2:204-11.

10 Xu DQX, Guilholt S, Galibert F. Restriction fragment length polymorphism of the human c-fms gene. Proc Natl Acad Sci USA 1985;82:2862-5.

11 Angert E, Nagarajan L, Huebner K. Previously unreported NcoI RFLP for human CSFiR. Nucleic Acids Res 1989;17:2153.

12 Polymeropoulos $\mathrm{MH}$, Xiao $\mathrm{H}$, Rath DS, Merril CR. Dinucleotide repeat polymorphism at the human protooncogene CSF-1 receptor (CSF1R). Nucleic Acids Res 1991;19:1160.

13 Naylor SL, Helin-Davies D, Charoenworawat $P$, Villarreal XC, Long GL. The human osteonectin gene (OSN) has TaqI and MspI polymorphisms. Nucleic Acids Res 1989;17:6573.

14 Murray JC, Smith RF, Ardinger HA, Weinberger C. RFLP for the glucocorticoid receptor (GRL) located at RFLP for the glucocorticoid receptor (GRI)

15 Sambrook J, Fritsch EF, Maniatis T. Molecular cloning. A laboratory manual. Cold Spring Harbor, New York: Cold Spring Harbor Laboratory Press, 1989.

16 Lathrop GM, Lalouel JM, Julier C, Ott J. Strategies for multilocus linkage analysis in humans. Proc Natl Acad Sci USA 1984;81:3443-6. 